\title{
Evolution of Urology Services in Pakistan
}

\author{
Manzoor Hussain \\ Department of Urology, Sindh Institute of Urology and Transplantation (SIUT), Karachi, Pakistan
}

\begin{abstract}
Urology has been separated from its parent generic specialty at different times during the last 150 years in different countries. In Pakistan, from 1947 to 1970s, urology was part of surgery and was done by general surgeons. There were only two urology units from late 1950s to early 1960s. The actual rise of urology started with the introduction of trans-urethral resection of prostate (TURP) in 1980s with the introduction of endourology. Use of cystoscopy and retrograde ureteropyelography was in vogue much before TURP. The second era of modern endourology began with the introduction of percutaneous nephrostomy, ureteroscopy along with ESWL, and percutaneous nephrolithotomy in late 1980s and 1990s. Renal transplantation started in 1979 from living-related donors in public sector hospitals. Now, there are 19 centres in the country performing regular renal transplantions. Urology has undergone a dramatic change during the new millennium. There have been sub-specialties in urology, like paediatric urology, endourology, reconstructive urology, uro-oncology, laparoscopic and robotic urology. At present, there are 11 specialised kidney centres and institutes of urology in the country and 25 recognised urology centres for FCPS. More such centres and replication of the SIUT model is expected in Pakistan.
\end{abstract}

Key Words: Urology, Endourology, Transplantation, Pakistan.

How to cite this article: Hussain M. Evolution of Urology Services in Pakistan. J Coll Physicians Surg Pak 2021; 31(06):746-748.

The history of urologic disease is as old as the human being itself. Vesical stones were found in Egyptian mummies, approximately 7000 yearsago. Circumcision is one of the oldest urological procedures, practised by barbers and technicians in $90-95 \%$ cases in Pakistan. ${ }^{1}$ Other older urologic operations included catheterisation with rubber catheters, dilatation with metallic bougies and diagnostic uroscopy. In the old history books of urology, there is no mention about Pakistan; however, archaeological excavations in Harappa (Punjab) and Mohen-Jo-Daro (Sindh) revealed ample evidence of urban culture, but there is no trace of famous urologists from areas now constituting Pakistan before $1947 .^{2}$

Pakistan is situated in South Asia with a population of about 207.8 million. The oldest paper on the causation of stones in India was published by in 1931, showing the highest incidence of stone disease in Dera Ghazi Khan, Sukkur and Hyderabad districts now in Pakistan - in the entire subcontinent. ${ }^{3}$

Urology from 1947 - 1970s was mainly considered a part of general surgery and was done mainly by general surgeons, comprising open stone surgeries and open prostatectomy. Reconstructive surgeries in urology were done by plastic surgeons and consisted primarily of hypospadias, epispadias, phaloplasty, and skingrafting, to cover genitalia after trauma.

Correspondence to: Dr. Manzoor Hussain, Department of Urology, Sindh Institute of Urology and Transplantation (SIUT), Karachi, Pakistan

E-mail: hmanzoor2015@gmail.com

Received: November 14, 2020; Revised: December 23, 2020; Accepted: January 06, 2021

DOI: https://doi.org/10.29271/jcpsp.2021.06.746
There were only two Urology units from late 1950s to early 1960 s in the country. One of them was in Civil Hospital, Karachi, while the other was in King Edward College Hospital, Lahore. The other units where urology was being practised were Liaquat National Hospital and Holy Family Hospital in Karachi. In Peshawar, urology unit was established in Lady Reading Hospital in 1976; later on, new unit was established in Khyber Teaching Hospital, Peshawar. Department of Urology, Rawalpindi Medical University is the oldest urology unit in northern Punjab, established in 1970 and performed the first renal transplant in Pakistan. Armed Forces Institute of Urology (AFIU), another urology centre in Punjab, was established in 1996 to cater to the needs of patients with nephrological and urological diseases in Rawal pindi / Islamabad area. Their parent department at $\mathrm{CMH}$, Rawalpindi, performed the first renal transplant in 1979 and by 1985, they had performed 100 live-related renal transplants. ${ }^{4}$

During the above period, urology mainly comprised of catheterisation, urethral dilatation, open surgery for stones and open prostatectomy. The actual rise of urology began with the introduction of TURP in the country, which made a clear distinction between general surgeons and urologists in early 1980s. This was the beginning of endourology. Use of cystoscopy, retrograde ureteropyelography and later, TURBT/TURP, made the separation of urology from general surgery.

The second era of modern endourology began with the introduction of percutaneous nephrostomy in 1997, and ureteroscopy along with ESWL in 1987-1989. In 1997, percutaneous nephrolithotomy (PCNL) was started in Karachi. ${ }^{5}$ Earlier, it had started in 1992 in Sadiqabad, which was probably the first 
centre for this procedure in Pakistan. Now, PCNL is being done for renal calculi at 58 urology units and ESWL in around 25 units. In 1998, Pakistan association of urologic surgeons (PAUS) was founded in a national meeting of urologists in Lahore. Now, there are 700 members of PAUS, some of them working overseas.

Renal transplantation in Pakistan was started in 1979 from living-related donors in public sectorhospitals. The Transplantation of Human Tissues and Organs Ordinance 2007 was promulgated by President of Pakistan in November, 2007, to enable ethical transplantation and to curb illegal trade of organs. Now, there are approximately 19 centres in the country where renal transplantation is being performed. The largest public sector centrefortransplantation is Sindh Institute ofUrology and Transplantation (SIUT), where > 6200 renal transplants have been performed since 1986, including four cadaveric kidney transplants harvested locally from Pakistan.

In Pakistan, there are around 700 qualified urologists, and about 25 urology departments recognised for fellowship in urology training by College of Physicians and Surgeons Pakistan (CPSP). FCPS is $2+3$ or $2+4$ year programme and MS urology is a 5-year programme. Masters in Surgery (MS) programme is currently being offered in 9 reputed universities in Pakistan.

Urology has undergone a dramatic change during the new millennium. There have been sub-specialties in urology like paediatric urology, renal transplant urology, endourology, reconstructive/urodynamics urology, andrology and male infertility, and uro-oncology. There are only three paediatric urology centres in the country. ${ }^{6}$ There are 6-7 centres offering laparoscopy in urology. At one centre, SIUT, robotic surgery is currently being offered. Laparoscopic donor nephrectomy is also performed in SIUT.

Special clinics for urethral reconstruction and functional urology were opened in 1970 and 2019, respectively, in a tertiary care centre in Karachi. Female urology (uro-gynecology) programme as a sub-specialty is open in about 5-7 centres in Sindh. There are a few centres in Punjab, where special clinics are run for female urology and vesico-vaginal fistula (VVF) repair along with a VVF centre in Quetta, Balochistan and also 1-2 centres in KPK. A specialised stone clinic has been established for follow-up, metabolic workup and prevention of stone disease at SIUT.

In endourology, TURP, TURBT, PCNL, and URS are being done in all CPSP recognised teaching centres. Male infertility and andrology is not much practised in public sector urology centres. Testicular biopsy, vasogaphy, varicocele ligation, archeopexy, hormone therapy for hypogonadism, phosphodiesterase inhibitors, and intracorporal injections for erectile dysfunction are in practice in some public sector hospitals. Penile prosthesis and assisted reproductive techniques are not offered in public sector hospitals. These interventions are, however, offered in private sector in Karachi and in Lahore, with one-yearfellowship programme is offered in Lahore.
Academics and research are not well-developed in urology in Pakistan; most urologists do not seek academic and research programmes because of their busy clinical schedules and no financial benefits. There is no urology journal in Pakistan.

The classical surgical training follows the apprenticeship model. However, during the past few decades, there is rise in minimally invasive surgery (MIS) and concurrent rise in medicolegal concerns and patient safety, and there is shift toward adaptation of surgical simulation labs. ${ }^{7}$ There are around 3-4 skill labs in tertiary care centres in Pakistan, which are offering training in endourology and dry labs in training basic laparoscopy in urology. We expect to see more such skill labs for training and also training in classical ways to retain open surgical skills in stone disease for large renal calculi, large renal tumors and difficult nephrectomies for large pyonephrotic kidneys, urological trauma, and renal transplantation.

The future of urology is exciting and more technology will be acquired in Pakistan. MIS will rise in the future for stone disease and uro-oncology in the form of laparoscopy and robotics and retrograde intrarenal surgery. More tertiary care centres will be opened in future in Pakistan in public sector because private sector treatment is expensive and beyond the reach of $80 \%$ of disfranchised population. It is felt that SIUT model (run by government and public jointly) will be replicated in the form of a beacon for free healthcare in Pakistan. ${ }^{8}$ The author hopes to see the deceased organ donation programme to be started in near future. This will reduce the commercialisation in transplantation and open new centres for other solid organ transplants after passing of cadaveric law by the Parliament in Pakistan in 2010. It is expected that medical treatment for incontinence, lower urinary tract symptoms, erectile dysfunction, stone prevention and targeted therapy in uro-oncology. Medical urology will be a new subspecialty in urology. There will be a rise in computer-based technology to transmit new ideas and research within Urology. There will be an increasing role of PAUS in teaching, training and medical education in the near future with more global cooperation. As more female urologists will be produced in future, we expect to see more specialised centres for 'female urology' in Pakistan.

In conclusion, we see a paradigm shift in training and teaching in urology from old apprenticeship model to simulations to dry and wet lab-based training. The author foresees an increasing number of urologic consultants and shifting simple urologic operations to primary care setting rather than large tertiary care hospitals, as an increasing number of institutions for urologic diseases in Pakistan is seen in future. A rise in MIS and robotics and medical urology as a subspecialty are seen in near future.

\section{ACKNOWLEDGEMENT:}

I am highly thankful to Dr. Qurat-ul-Ain Ghori for her help in typing this manuscript.

\section{CONFLICT OF INTEREST:}

The author declared no conflict of interest. 


\section{AUTHOR'S CONTRIBUTION:}

MH: Conception, drafting, final critical review and final approval.

\section{REFERENCES}

1. Rizvi SAH, Naqvi SAA, Hussain M, Hasan AS. Religious circumcision: A muslim view. BJUI 1999; 83Supple 1:13-6. doi: 10.1046/j.1464-410x.1999.0830s1013.x.

2. Das S. Sushruta, the pioneer urologist of antiquity. J Urol 2001; 165(5):1405-8.

3. McCarrison. A lecture on "The Causation of Stone in India". British Med J 1931; 1(3675): 1009-15.

4. http://www.pulsepakistan.com/index.php/main-news-may -1-16/1590-international-preceptor-ship-program- launched-in-pakistan. Accessed on: 22 December 2020.

5. Rizvi SAH, Hussain M, Askari SH, Lal M, Zafar MN. Surgical outcomes of percutaneous nephrolithotomy in 3402 patients and results of stone analysis in 1559 patients. BJU Int 2017; 120(5):702-9. doi: 10.1111/bju.13848.

6. Sultan S. Evolution of paediatric urology at Sindh Institute of Urology and Transplantation. Frontiers Paediatrics 2014; 2:88. doi: 10.3389/fped.2014.00088.

7. Ather $\mathrm{MH}$, Siddiqui T. Urology training in the developing world: The trainer's perspective. Arab J Urol 2014; 12(1):64-67. doi: 10.1016/j.aju.2013.07.001.

8. Burki T. A beacon for free healthcare in Pakistan. BMJ 2016; 352:1681-2. doi: 10.1136/bmj.i1681. 